IBIMA Publishing

Journal of Administrative Sciences and Technology

http://www.ibimapublishing.com/journals/JAST/jast.html

Vol. 2017 (2017), Article ID 106163, 10 pages

DOI: $10.5171 / 2017.106163$

Research Article

\title{
Fear, Greed and Lack of Trust In Online Financial Trade
}

\section{Tove Engvall}

Mid Sweden University, Department of Archives and Computer Science, Härnösand, Sweden

Correspondence should be addressed to: Tove Engvall; tove.engvall@miun.se

Received date: 7 September 2016; Accepted date: 18 November 2016;

Published date: 3 January 2017

Academic Editor: Liliana Mihaela Moga

Copyright (C) 2017. Tove Engvall. Distributed under Creative Commons CC-BY 4.0

\begin{abstract}
Trust is a crucial component in business relations, and also a precondition for people's adoption of electronic services. This study addresses challenges regarding trust in online financial trade. Results indicate that brokerage companies acting in a dishonest way, along with dominant patterns of fear, greed and lack of knowledge and awareness among clients, lead to frequent losses of money. Which leads to a lack of trust in brokers, brokerage companies and the business domain. The way technology is used increases the challenges of risk and an unequal relation between client and brokerage companies. Self-ethnography has been used as a method, where observations, interviews and conversations were performed. Suggestions are to do further research in order to identify how mechanisms for trustworthiness, accountability and transparency can be created in the business domain, in which management of records will play a central role.
\end{abstract}

Keywords: trust, online trust, online trade, digital records management

\section{Introduction}

The growth strategy Europe 2020 was developed in the aftermath of the financial crisis 2008, with the aim to deliver smart, sustainable and inclusive growth (European Commission, 2010a) in which the digital development is emphasized (European Commission, 2010b). In regards to financial crises, an understanding of trust and confidence can give insights for recovery, risk management and prevent future occurrences (Earle, 2009). In a digital context, and in this case in online trade, there is also specific trust challenges to consider. Beldad, de Jong \& Steehouder (2010) mean that trust is a precondition for people's adoption of electronic services, wherefore determinants for online trust are important to consider in design, implementation and management of infrastructures for online services. Perceived trust is an important preceding factor for customers' intentions to use online trade services, which is also substantiated by perceived security and privacy (Roca, García \& de la Vega, 2008). Lack of trust is seen as one of the main reasons for consumers to not make transactions or purchases online (Grabner-

Cite this Article as: Tove Engvall (2017), "Fear, Greed and Lack of Trust in Online Financial Trade", Journal of Administrative Sciences and Technology, Vol. 2017(2017), Article ID 106163,

DOI: $10.5171 / 2017.106163$ 
Kräuter \& Kaluscha, 2003; Urbana, Amyxb \& Lorenzon, 2009; Wang \& Emurian, 2004; Gefen, 2002; Shankar, Urban \& Sultan, 2002). Trust is seen as a driver in consumer loyalty (Hemphill, 2002) and is used in marketing strategies (Urbana, Amyxb \& Lorenzon, 2009). Trust is a theme that is explored in different fields and from different perspectives. Beldad, de Jong \& Steehouder (2010) mean that using an inclusive framework with all sociological, socio-psychological, socio-cultural and technical perspectives would be helpful and Wang \& Emurian (2004) are asking for an identification of crucial elements for the formation of online trust. From a societal perspective, a relevant area for examination would be to ask whether we can trust that the system actually delivers in accordance with democratically agreed visions, and if not - what are the problems that ought to be addressed.

\section{Objectives}

With the digital development, information acquires another meaning, wherein records are not just by-products of transactions, they also represent them (Lemieux \& Limonad, 2011). In a digital financial context, money and transactions are basically represented by information, wherefore records management becomes crucial, and also plays an important role in trust. The objective of this study is to explore the aspect of trust in online financial trade and identify areas for research in the field of archives and information science.

\section{Online trade}

Online trade can be defined as "the act of placing buy or sell orders for financial securities and/or currencies with the use of a brokerage's internet-based proprietary trading platforms." (Roca, García \& de la Vega, 2008, p. 97; Investopedia, 2016) The client works with a personal broker, whose role is to provide analysis of the market and assist the client (interviewee 4). The Foreign Exchange (Forex) Market is an online system trading in currencies, and is one of the biggest financial markets globally, with over $\$ 4$ trillion traded daily. Trades are made on the fluctuations on the market, thus one can earn (or lose) money both when the market goes up and when it goes down. Through the use of leverage, the amount won or lost can be increased. Leverage means utilizing, for example, 200 times more than the investments in the trades (FXGM, 2016). At many online brokerage platforms it is possible to trade in Forex, shares, indexes and commodities.

\section{Methodology}

The study is a self-ethnographic study, based on one year of fieldwork in online trade. The paper has an inductive approach and is discussed from an archives and information science perspective, wherefore it is also presented that way. The initiative Responsible Research and Innovation expresses the need for improvements in addressing current societal challenges in research (European Commission, 2016). One aspect of that is to get a clear understanding of a problem in a real life setting, wherefore the method was considered appropriate. An ethnographic study provides the means for "exploring, in-depth, people's beliefs, values and behaviors" (Williamson, 2013a, p. 288) and an understanding of how reality is constructed (Williamson, 2013b). Selfethnography is when the researcher, as an active participant, uses experiences and empirical material for research purposes (Alvesson, 2003). Systematic reflexivity was used during the research process and content analysis (Elo \& Kyngäs, 2007) was used in the analysis of research data. The study includes experiences from online trade with six different brokerage companies, where three of them are presented due to clear differences; an estimation of 75-100 oral conversations with brokers by phone or skype; additional written conversations mainly by Skype; an educational course in online trade; unstructured interviews with: seven brokers, an educator in trading (respondent 8), and a Digitization Minister in a European country. An ethical consideration about the method is how to relate to participants in the field (Bryman, 2002). The research is based on the experiences of the researcher, rather than being a study on an "other". Interviewees 
who were interested read the notes and/or draft of the paper.

\section{Online trade experiences}

Initially, the researcher had no experience of trading, no knowledge about how it works, about regulations or how to assess different companies offering their services.

\section{First example - an unregulated company}

Money that was transferred could not be traced for over a month; the company did not do what they had promised; it was impossible to withdraw money; it was impossible to reach the broker and no one else assisted. For companies regulated by CySEC (Cyprus Security and Exchange Commission), there is a process for complaints and an ombudsman to whom a client can apply for compensation. The European Consumer Centre's network can assist in mediating with companies, but they need a physical address to the company, which many unregulated companies don't have. When reported to the police, it was considered to be under civil law and therefore the client has to pursue the matter for oneself. The insurance company could cover for identity theft, but not fraud. There doesn't seem to be a working procedure to back up citizens in these situations and national jurisdiction make it complicated for the police to act. The financial supervisor has a warning list of suspected companies, but clients first of all need to know that the list exists.

\section{Second example - Regulated unstructured company}

This was a regulated company, but trading was performed in a very unplanned and "ad hoc" way. There was pressure to make large and frequent investments, no advice provided about risk or strategies, nothing was explained properly but rather just said what to do. When money was lost, other companies called and offered "recoveries" or juridical assistance. Withdrawal of money worked, there were people at the company to communicate with when communication with the broker failed and they had a process for complaints.
Information was later received that the broker was in jail for fraud.

\section{Third example - Regulated professional company}

The third example worked very differently. The broker did not give advice about what to do, but assisted by explaining things, calculating the risk and did not ask for big or further investments. Daily phone calls, fast replies on e-mail, invitations to weekly lectures on webinars and an attitude where it is the client who is making the choices. In the beginning, by applying what was learned in the trading course, it went well. But when not paying full attention, a couple of mistakes were made and the money was lost.

The first two examples gave the impression that no one is to be trusted, and the client is dependent on the broker. It was the broker who decided whether money could be withdrawn in the first example. In the second example, if one did not follow the broker's instructions, one was left to perform alone. In the third example, the relationship was very professional and the broker showed engagement in the results, but it is easy to lose everything anyway. Interviewee (8) commented in a lecture, that there are brokers who work for you and brokers who do what they can to make the client lose money.

\section{Observations}

Below are observations about the field, and some patterns that could be recognized from conversations with brokers from different companies.

The corporate structure can be difficult to understand from a client perspective. There seems to be different constellations involving various actors, and functions of the company can be localized in different countries. According to interviewee 4, the diffuse structure may be set up to avoid being accountable.

Communication is crucial. Since everything is performed online, control of communication channels allows companies 
to control client relationships. In some cases, the client could only leave a message and wait for someone to call back, or communicate by e-mail or Skype. Then it is up to the broker if he/she replies. Often several people from the same company call. Internal communication seems to vary greatly from company to company.

Information about clients is sold among companies, especially if a client has lost money. In that way people become like a trading asset. Accuracy and authenticity of the information, as well as timing, is very crucial for actual results in the trade. In order to start trading, the client must submit records for proof of identity, address, credit card details and a signed record of the amount deposited. Phone calls are recorded, for supervisory purposes. In most cases the client does not receive any signed records, but terms and conditions can be found on the company's website.

Technological development moves fast and as the minister with responsibility for digitization expressed; "technology beats politics", but politics can set some restrictions, show direction and bring issues to public debate (interviewee 9). It is important to continuously improve means for supervision, transparency on the Internet and also to consider the values dominating the financial sector. Values are built into the design and conduct of technological, recordkeeping and communication processes. Information and communication technologies provide possibilities for empowerment since they circumvent traditional hierarchies, but also risk instituting new patterns of domination. Technology makes things happen faster and also expands both gains and losses, which raises the level of risk.

Manipulation and trust seem to be occurring themes. According to interviewee 4 , some people have the capacity to deliver the energy that will manipulate people in the direction they want.

Manipulation could, for example, be identified in the way of speaking, giving compliments, lying, and talking about the value of trust, but acting differently. In that way, creating a feeling of trust can put the client in a vulnerable position and effectively give control to the broker and company.

Trust has to include both trust in oneself and trust in the relationship between the broker and client. Trust has been mentioned as a prerequisite for a client to choose to invest money, thus many brokers try to create that feeling by proving that they are reliable. What is required, however, is to create a trustworthy system with mechanisms that apply when things don't work.

Various strategies are used to make a client invest money. For example the use of bonuses, boosting excitement about money and stressing opportunities, which boosts fear of losing opportunities as well as amplifying greed. Interviewee 4 said that some companies take advantage of people's fear and greed. Companies and brokers taking advantage of people are themselves motivated by greed and the idea that you have to use others to get what you want instead of having trust in themselves.

Although there seem to be some companies and brokers who act unscrupulously, there are also those who care about and want to help their clients. Being a broker in an environment of fear, greed and high level of competition is probably not easy and requires a level of personal strength to handle clients, as well as requirements from the company, regulations, and other brokers. In such a setting, a framework for trustworthiness would be helpful.

\section{Interviews}

Conversations with brokers revealed that a major problem is that people lack trust because of experiences of losing money and bad manners of people and companies encountered.

\section{Trust between brokers and clients}

All interviewees highlighted the problem caused by the brokers that make clients 
lose money, which ruins their trust in the business and brokers. Consequently their job becomes harder. Pushing for big investments, give misleading information, merely tell the client what to do without taking time to explain properly and the use of bonuses attached with conditions for withdrawals are some of the patterns that were highlighted. They stressed the importance of empowering clients to make their own decisions, and building confidence and trust in themselves (interviewees 2, 4, 5 and 8). All the interviewed brokers stressed that their interest is to assist the clients to make profit, and their intention is to build a longterm relationship.

Important to creating trust is that the client can see results (interviewees 1,6 ), the way the broker treats the client and if the signals are good (interviewee 1). Interviewee 5 stressed that a success factor is that he truly cares about his clients. Speaking the same language, compatibility and developing a personal relationship (interviewee 2, 8) was also highlighted. Trust is built over time (interviewee 4) and when the client recognizes that there is someone who is concerned about the account, trust will increase (interviewee 8). Knowing the reputation of the company helps clients to decide whether to entrust their money to the company. According to interviewee 6 , the company he works for has been in the market for a long time and that in itself creates trust. They have experience, are professional and have knowledge and credibility. His advice to clients is to see if the company is regulated, if it provides education, if sufficient information is provided, if they develop a trading plan, if they explain things properly so the client knows what is happening.

\section{Risk management}

According to the interviewees, the main reason for clients losing money is when they make decisions based on fear or greed and not knowing what they are doing. It is important to talk about and calculate risk, and education and continuous learning is important (interviewee 3, 4, 6, 7, 8). Volatility, volume and leverage are some of the things to consider in regards to risk. Having enough margin in the account in order to have space for movements on the market, making a trading plan, open positions you believe in after having done calculations and analysis, and being patient are success factors (interviewee 8). The psychological challenge is the biggest, as well as too high expectations of how much it is possible to make with the amount invested. The greatest challenge is when people start trading, before they have confidence and ability to really understand how it works, which makes them take too high risk. Everything can be lost with just one trade if it goes wrong (interviewee 8).

\section{Regulatory environment}

MiFID (Markets in Financial Instruments Directive) is a European law regulating trade (interviewee 1,6). There are also regulations that govern licenses to conduct business, and it is common to have a license from CySEC (Cyprus Security and Exchange Coalition) (interviewee 4). Each country has its own regulations and financial supervisors (interviewee 4). According to interviewee 3 , London has the highest regulation, and is also most prestigious. Having a license makes it safe for the client, since it shows that it is legal. The regulations were seen to be too weak, but are becoming stronger (interviewee 3, $4,8)$, and brokers who are discovered to act in a bad manner are suspended immediately. It was suggested that financial supervisors should have more mandatory rights and conduct more audits, which would make the companies act more carefully (interviewee 6). Transparency of information provided to clients (interviewee 6) and research about the regulatory environment (interviewee 3) were requested. Interviewee 4 suggested that it should be mandatory for companies to have a physical office in the country in which they are operating, that they deposit a certain amount of money in a bank in that country and that the national financial supervisor should have the authority to control it. According to interviewee 6, unregulated companies can do almost anything they want with clients' money 
and there are ongoing conversations about what can be done to handle that (interviewee 6).

\section{Information management}

Online trade is an information intensive and sensitive domain, dependent on good information, which is also expensive (interviewee 1) and timing is crucial to success (interviewee 6). Interviewee 5 noted that that the quality of the information as well as the business processes and how the information is managed create trust. If the company is managed well, it also makes him trust the information. Interviewee 6 stressed that providing information to the client is very vital in building trust. According to interviewee 8 , the critical issue in terms of management of personal data is not when the client has an account with a brokerage, because this is regulated. However, there is a market for trading information about people. Apps on mobile phones collect a lot of information: where you are, what you buy, where you spend your money, your age, what apps you use, your fingerprints, face recognition and more. Information compilations are sold to companies looking for targeted groups of potential clients. Therefore trust in your phone provider is also an important consideration.

\section{Virtual markets}

According to one of the interviewees, 95\% of clients lose money. Many times, their money doesn't get to the real market, but rather a virtual one. In that way, if a trade is lost, the money goes to the company. The use of CFD (contracts for difference) is one way of creating a virtual market, and implies a high risk of losing big amounts of money. Therefore it will for example be prohibited in USA. He means that first the brokerage company decides whether the client can be on the real market, then the bank make decisions and they are manipulating the market a lot. He means that the entire market is a fraud. It is manipulated to make regular people lose money which goes to the big banks. It is a closed system where someone has to lose money for someone to make profit.

\section{Sustainability}

Sustainability can be addressed from different perspectives. What was stressed in the interviews was that all companies must "put everything on the table and do fair play" (interviewee 6), and they have to manage and talk about risk, not just profit. Honesty, transparency (interviewee 6), as well as building knowledge, confidence and trust will be more sustainable in the long run. About the question of what effect the financial market has on a more or less sustainable development, interviewee (3) meant that he didn't think trade has a direct effect. But you can invest the money you make in companies so they can develop and invest in new technologies for example, and there are a lot of people who donate money to charity. Interviewee 1 works at a company which donates a percentage of their profit to various NGOs around the world. Interviewee (4) asserted that online trade will never be sustainable, because of the virtual "bubbles" in which people lose money. 95\% risk of losing money is not sustainable.

\section{Records and financial stability, transparency and accountability}

Records are information that has certain values, and can be in different mediums and formats. Records are created in the course of activities and transactions and function as evidence, if they are managed in a way that maintains their authenticity and reliability. A reliable record means that its contents are accurate, and authenticity means that the record is what it claims to be. Trustworthy records management implies procedures that ensure these qualities (Swedish Standards Institute, 2016). The value of records as evidence serves many purposes. They are a tool enabling accountability of people's actions; for "honest, responsible, upright and transparent conduct of human affairs" (Hurley, 2005, p. 226). Records are also a means for control and power and shaping people's behaviors (Ketelaar, 2005). Ensuring the quality of records in an online environment is complex and the international InterPARES Trust Project (Trust in Digital Records in an Increasingly 
Networked World) (InterPARES Trust, 2016) researches in this field. As to the financial domain, records and records management have a crucial role in enabling transparency and accountability, managing risk and external supervision, as well as ensuring financial stability (Lemieux, 2010; Coleman, Lemieux, Stone \& Yeo (eds.), 2011). It makes it possible to "effectively monitor financial risks, make good risk decisions, and hold individuals and institutions accountable when rules on risk tolerance levels are breached" (Lemieux, 2011 , p. 4). Financial crisis not only depends on risks at the financial markets, but is also an effect of organizational problems, resulting from how financial technologies are applied and financial records are managed (Lemieux, 2011). Poor recordkeeping, on the other hand, contributes to a build-up of risk in the financial system (Lemieux \& Limonad, 2011). Research on the bank collapse in Jamaica 2008 shows that poor recordkeeping led to a lack of accountability, and as a result of that, weak internal control and inability to make effective decisions. Which led to operational inefficiencies - which together with external factors led to the bank collapse. Absence of good records also complicated supervision and rehabilitation efforts (Lemieux, 2001). Management of risk is often closely related to recordkeeping and sometimes seen as almost the same (Lemieux, 2010b). Deficiencies in information control increase risk of failure in compliance with regulations, financial loss and damage of reputation (Adams, 2011). Market conditions 2008-2009 that highlighted weaknesses in control systems of financial institutions, also raised the need for increased transparency and sharing of information (Cunningham-Day \& Didizian, 2011).

\section{Discussion}

Results from the study indicate that there are severe challenges in online trade in regard to trust. Misbehavior of companies and brokers, fear, greed and lack of awareness characterizing people's decisions, and high risks in the way technology is used, have made many people lose big amounts of money. There is a lack of trust, not only between people, but also in oneself and the entire system, which also makes it difficult for serious brokers to work. Clients are placed in a vulnerable position in a complex context, where the management of information and communication is crucial, and also how the technology is used.

What is required is to create a framework for trustworthiness in the business domain which includes individuals, business relations as well as the technological and societal context. Instead of being a possibility, it tends to create the opposite now. The idea of using money to make money and using information and technology in that process could provide a way to create smart, sustainable and inclusive growth - theoretically. But if 95\% are losing money, people are being manipulated, the system is being manipulated, and technology is used to strengthen the power and control of financial institutions, then it is neither sustainable, smart nor inclusive. There is a need for greater transparency and accountability to shed light on practice in the online financial markets, as well as mechanisms for making actors responsible for their actions. Recordkeeping plays an important role in that, and also functions as a control instrument in managing risks, both on an individual level, in business relationships, and on a societal level.

\section{Suggestions for further research}

Mechanisms for accountability contribute to creating trust and also reduce the impact of fear and greed. Fear and greed not only cause individuals to lose money, they are also used to take advantage of people. A more sincere analysis of deficiencies in trust can provide clues about where improved accountability measures are needed, as well as improving the means for control and transparency. Re-evaluating records requirements in different processes in regards to trust, accountability, transparency and management of risk is recommended. How technology, as well as records management 
and communication strategies are designed and performed ought to be considered from a power perspective. A clearer direction of people's intention and purpose in making money - to create a sustainable growth for the future, both on an individual and societal level - might also contribute to reducing greed and replacing it with other more constructive values.

\section{References}

- Adams R. (2011). Information privacy in the USA. In Coleman, L., Lemieux, V. L., Stone, R. \& Yeo, G. (Eds.), Managing Records in Global Financial Markets: Ensuring Compliance and Mitigating Risk (pp.77-87). London: Facet Publishing, 2011.

- Alvesson M. (2003). Methodology for close up studies - struggling with closeness and closure. Higher Education, vol. 46. pp. 167-193

- Beldad, A., de Jong, M. and Steehouder, M. (2010). How shall I trust the faceless and the intangible? A literature review on the antecedents of online trust. Computers in Human Behavior 26, pp.

857-869

- Bryman

A.

(2002).

Samhällsvetenskapliga metoder. [Social science methods.], Liber, Malmö

- Coleman, L., Lemieux, V. L., Stone, R. and Yeo, G. (Eds.). (2011). Managing Records in Global Financial Markets: Ensuring Compliance and Mitigating Risk. London: Facet Publishing.

- Creswell, J. W. (2007). Qualitative inquiry \& research design. Choosing among five approaches. Sage Publications, London, United Kingdom.
- Cunningham-Day, J. and Didizian, M. (2011). Data exchange and confidentiality: an Asia Pacific perspective. In Coleman, L., Lemieux, V. L., Stone, R., \& Yeo, G. (Eds.). Managing Records in Global Financial Markets: Ensuring Compliance and Mitigating Risk (pp. 61-75). London: Facet Publishing.

- Earle, T. C. (2009). Trust, Confidence, and the 2008 Global Financial Crisis. Risk Analysis, Vol. 29, No. 6, 2009. DOI: 10.1111/j.15396924.2009.01230.x

- Elo, S. and Kyngäs, H. (2007). The qualitative content analysis process. Journal of Advanced Nursing 62(1), pp. 107-115. doi: $10.1111 / \mathrm{j} .1365-$

2648.2007.04569.x

- European Commission (2010a). Europe 2020. A strategy for smart, sustainable and inclusive growth http://ec.europa.eu/europe2020/i ndex_en.htm (Accessed 22 August 2016)

- European Commission (2010b). Communication from the Commission to the European Parliament, the Council, the European Economic and Social Committee and the Committee of the regions. Brussels, 19.5.2010 Downloaded from http://eurlex.europa.eu/legalcontent/en/ALL/?uri=CELEX\%3A 52010DC0245 (Accessed 22 August 2016)

- European Commission (2016). Horizon 2020. Work Programme 2016-2017. 16. Science with and for Society. (European Commission Decision C(2016)4614 of 25 July 2016)

Downolad from http://ec.europa.eu/research/part 
icipants/data/ref/h2020/wp/201

6_2017/main/h2020-wp1617-

swfs_en.pdf (Accessed 22 August 2016)

- FXGM (2016). Welcome to FOREX ebook. FXGM.

Downolad from www.fxgm.com (Accessed 31 August 2016)

- Gefen, D. (2002). Reflections on the Dimensions of Trust and Trustworthiness among Online Consumers. Newsletter ACM SIGMIS Database. Vol 33, Issue 3, pp. 38-53

doi $>10.1145 / 569905.569910$

- Grabner-Kräuter, S. and Kaluscha, E. A. (2003). Empirical research in on-line trust: a review and Critical assessment. Int. J. HumanComputer Studies 58, pp. 783-812

$\bullet$

Hemphill, T. A. (2002). Electronic Commerce and Consumer Privacy: Establishing Online Trust in the U.S. Digital Economy. Business and Society Review 107:2, pp. 221-239

- Hurley. C., (2005). Recordkeeping and accountability. In: McKemmish, S., Piggott, M., Reed, B. \& Upward, F. Archives: Recordkeeping in Society, Wagga Wagga, New South Wales.

- InterPARES Trust. Accessed 15 August 2016 at www.interparestrust.org Investopedia (2016). Online Trading.

Accessed at http://www.investopedia.com/ter $\mathrm{ms} / \mathrm{o} / \mathrm{onlinetrading} \cdot \mathrm{asp} ? \mathrm{ad}=\operatorname{dirN} \&$ $\mathrm{qo}=$

investopediaSiteSearch\&qsrc $=0 \& 0$ $=40186$ (Accessed 20 August 2016)

- Ketelaar, E. (2005). Recordkeeping and societal power. In: McKemmish, S., Piggott, M., Reed, B. \& Upward, F. Archives: Recordkeeping in Society, Wagga Wagga, New South Wales.
- Lemieux, V. L. and Limonad, L. (2011). What 'good' looks like: Understanding records ontologically in the context of the global financial crisis. Journal of Information Science, 37 (1), pp. 2939

Lemieux, V., L. (2001). Competitive Viability, Accountability and Record Keeping: A Theoretical and Empirical Exploration Using A Case Study of Jamaican Commercial Bank Failures (Doctoral Thesis) University College London, Faculty of Arts

- Lemieux, V., L. (2010). Notes and Communications "Always Follow the Money": A Call for Investigate Financial Records. Archivaria, spring 2010, pp. 173-188

- Lemieux, V., L. (2010b). The records-risk nexus: exploring the relationship between records and risk. Records Management Journal, vol 20, pp. 199-216

Lemieux, V., L. (2011). Records and Information Management for Financial Analysis and Risk Management: An Introduction. The workshop on Records and Information Management for Financial Risk Analysis and Management, Vancouver, Canada, 24-25 Au-gust 2011.

- Roca, J. C., García, J. J. and de la Vega, J. J. (2008). The importance of perceived

trust, security and privacy in online trading systems. Information Management \& Computer Security Vol. 17 No. 2, pp. 96-113

- Shankar, V., Urban, G. L. and Sultan, F. (2002). Online trust: a stakeholder perspective, concepts, implications, and future directions. Journal of Strategic Information Systems 11, pp. 325-344 
$\bullet$

Swedish Standards Institute (2016). ISO 15489-1. Information and documentation - Records management - Part 1: General

- Urbana, G. L., Amyxb, C. and Lorenzon, A. (2009). Online Trust: State of the Art, New Frontiers, and Research Potential. Journal of Interactive Marketing 23, pp. 179190

- Wang, Y. D. and Emurian, H. H. (2004). An overview of online trust: Concepts, elements, and implications. Computers in Human Behavior 21, pp. 105-125

- Williamson, K. (2013a). Ethnographic research. In Williamson, K. \& Johanson, G. (Eds). Research Methods. Information, Systems and Contexts. Tilde Publishing and Distribution, Prahran, Australia

- Williamson, K. (2013b). Research concepts. In Williamson, K. \& Johanson, G. (Eds). Research Methods. Information, Systems and Contexts. Tilde Publishing and Distribution, Prahran, Australia 